\title{
Risks identification and ranking using AHP and group decision making technique: Presenting "R index"
}

\author{
Safar Fazli ${ }^{\mathrm{a}}$ and Mehrdad Mansourdehghan ${ }^{\mathrm{b}^{*}}$
}

${ }^{a}$ Assistant professor of Imam Khomeini International University, Qazvin, Iran

${ }^{b}$ MA student of Management, Imam Khomeini International University, Qazvin, Iran

\section{HRO N I C L E}

Article history:

Received July 25, 2012

Accepted October 10, 2012

Available online

December 82012

$$
\text { Keywords: }
$$

Risk, Prediction

Risk identification

Risk importance

$R$ index

Risk ranking

\begin{abstract}
A B S T R A C T
One of the primary concerns in project development is to detect all sorts of risks associated with a particular project. The main objective of this article is to identify the risks in the construction project and to grade them based on their importance on the project. The designed indicator in this paper is the combinational model of the Analytical Hierarchal Process (AHP) method and the group decision - making applied for risks measurement and ranking. This indicator is called "R" which includes three main steps: creating the risks broken structure (RBS), obtaining each risk weight and efficacy, and finally performing the model to rank the risks. A questionnaire is used for gathering data. Based on the results of this survey, there are important risks associated with construction projects. There we need to use some guidelines to reduce the inherent risks including recognition of the common risks beside the political risks; suggestion of a simple, understandable, and practical model; and using plenty of the experts and specialists' opinions through applying step. After analyzing data, the final result from applying $\mathrm{R}$ index showed that the risk "economic changes / currency rate and inflation change" has the most importance for the analysis. In the other words, if these risks occur, the project may face with the more threats and it is suggested that an organization should centralize its equipment, personnel, cost, and time on the risk more than ever. The most obvious issue in this paper is a tremendous difference between an importance of the financial risks and the other risks.
\end{abstract}

\section{Introduction}

A project is considered as an attempt to develop one product or to offer services (Ralph et al., 2010), which have some characteristics including start date, expiration date, objectives and measurable scales and a series of logical relationships. According to environmental conditions, existing risk in construction project is undeniable and mostly is a result of weak performance in controlling project and increase in cost as well as time delay, which leads to project failure. There are many environmental conditions, which are uncontrollable and it is clear that risk occurs in project because of various reasons, which are mostly unpredictable (Webb, 2003).

* Corresponding author.

E-mail addresses: m3hrdad.66@gmail.com (M Mansourdehghan)

(C) 2012 Growing Science Ltd. All rights reserved.

doi: $10.5267 /$ j.msl.2012.12.008 
Risk happens when a condition or an event has a negative or positive effect on objectives of project when it happens (Project Risk Management Handbook, 2007). The risk can be manageable, transferable, acceptable or reducible, but it is not often possible to be eliminated (Lam et al., 2007). Risk occurs in construction project and it includes different factors including political, economic, culture, commercial and technical, which may be as the result of government employer and/or contractor (Khazaeni et al., 2012).

It is often difficult to find construction project risks and hence should be managed, properly. Therefore, successful project manager is the person who determines natural project features and controls riskiness in project, properly. Risk management is an effectual tool in order to respond and to control a risk and we can called it as a systematic process in determining, analyzing and responding to project risks to increase positive result and to decrease negative consequences (Newton, 2008). The first step before a project is initiated is to make an assessment in project risk components (Makoei et al., 2007). Some experts believe that the most difficult part of risk management process is to determine risk components, because if the risk cannot be determined, the next steps will be ineffective (Burkeh, 1999). It is evident that many risks could be identified in this step, but risk identification is not sufficient, because project managers often require classifying risk based on their relative importance and their impacts on project, therefore the primary objective on risk will be based on their premierships in the next steps of risk management, which leads to better risk management. Many traditional methods have been introduced to identify and to classify risk components (Makoei et al., 2007), which could not cover restrict and steps of risk management process required enough attention and precision. Therefore, the modern techniques are based on group decision-making and using specialize and expert's experiments and supervision.

The method used in this paper uses hierarchal analysis and group decision-making for risk classification. The primary goal of this paper is to identify risks in the construction project and their premiership based on their relative importance in the project. In the next part of paper, first we consider research literature. Then research method and considered indicators will be described and the following, the indicator will be applied on a real project and analyzed. Finally, managerial suggestions and conclusion will be presented.

\section{Theoretical framework of research and offering conceptual model}

It is often necessary to find the root for different risk components associated with various projects (Chapman, 2006). Risk identification is a key phase of risk management (Ibrahim et al., 2006), hence several researchers have analyzed risk and its source and the common point of these researches is to focus the risk identification. Because of the fact that risk cannot be identified a head of time, project managers often try to find risks over a time (Jiahao Zeng et al., 2007).

Dias and Ioannou (1995) stressed that the project require risk source analysis through project. Ashley and Bonner (1987) considered the political risk in the construction project and analyzed political risk source, since they believed that the most important risk components in many projects are political issues in project. Kapila and Hendrickson (2001), in their study analyzed the financial risk in an international construction project whose most important goal was to examine currency exchange effect in construction project. Jiahao Zeng et al. (2007) introduced financial factors for measuring risk. According their opinion, the goal of designing this index is to structure two parameters; occurrence probability of risk and occurrence intensify of risk. The most important research results, which they found was the importance of using a group decision-making and risk analysis and it is believed that most previous methods which did not apply such a logic, are not proper for risk analyzes in real world. The direct use of engineers and expert's knowledge based and direct judgment by phase words, are the most important achievement of this work, but this model was very complex, which makes it impractical for practitioners. Jebel Ameli et al. (2005) analyzed various methods of multi criteria decision-making to analyze project risks and compared different types of multi criteria 
decision-making methods in ranking and identifying risk components. They argued that the issues associated with decision risks could be considered in the area of multi criteria decision making. However, their work did not have enough validity and justifiability to be used in practice because the researchers used TOPSIS method, which suffers from some disadvantage. Sebastian Maniasi et al. (2006) worked on the numeral taxonomy for risk identification where risk identification cycle includes a check-list, which classifies the risk in different classes in structured form. They offered a new model for risk identification and for risk classification in different classes and increased reliability level in risk identification and implied an acceptable justifiability among variables. Nevertheless, there is not a complete definition for model and, in fact, this model was not designed for all kinds of organizations. Long and Fischhoff (2000) introduced a model for identification and classification of important aspects of risks in various industries. According to researcher's opinions, this model helps rank risk component in term of certain condition and in diverse positions. One of the advantages of this model is to classify risks based on their nature and essence of risky activities in any project. In addition to risk, identification can define strategies alternatives for each risk scenario. Any organization with any structure can apply this model to classify risk. However, specialist and experts' opinions are not used for risk identification and risk analysis.

Daniel (2011) tried to identify and rank key factors or risk with the help of gathered data from experts and specialists in the industry of construction project in Hong Kong. The paper offered a 4-level analysis framework including statistical definition, Kendall test, Spearman test, and Mann-Whitney test. Researchers found that client, contractors and consultant have some participation in several factors of risk creation in the construction projects. The advantage is that we have better and knowledge trend and view towards construction project and its costs and relevant risk and attempt to control and respond to high level risk and it takes advantage of experts and specialists' supervision. Regarding the mentioned studies in the field of risk identification and risk gradation, we can introduce a model, which not only is public, simple and understandable for managers in projectcentered organization, but also it maintains appropriate, reliable and justifiable approach in terms of tools used based on experts and specialists' opinions. This model has designed for measurement and gradation of construction project risk. In other words, we can offer a model while measures risks based on expert's ideas and projects feature and identify theme (Webb Alan, 2003). The emphasis of this is on one main question that how organization can classify risks based on their influences an project, by identifying and comparing risk.

\section{Research methodology}

\subsection{Introductions of project and experts}

\subsubsection{Introduction of experts}

In this research, we gather some experts' insights who have been involved for development of different projects. Table 1 shows details of the experts' management positions.

Table 1

Experts' backgrounds

\begin{tabular}{lllllll}
\hline Specialist & $\begin{array}{l}\text { Project } \\
\text { manager }\end{array}$ & $\begin{array}{l}\text { Senior } \\
\text { engineer }\end{array}$ & Construction & $\begin{array}{l}\text { Senior Financial } \\
\text { engineer }\end{array}$ & $\begin{array}{l}\text { Senior } \\
\text { Designer }\end{array}$ & $\begin{array}{l}\text { Senior Civil } \\
\text { engineer }\end{array}$ \\
\hline Numbers & 1 & 2 & 2 & 2 & 2 & 3 \\
\hline
\end{tabular}

\subsubsection{Introduction of project}

The project is chosen from the Boiler Mapna Company, establishment of combinational cycle powerhouse. The primary employer of project is department of energy and the secondary employer is Mapna company and the place where there project is performed is located $35 \mathrm{~km}$ away from Tehran, the capital city of Iran. The mentioned powerhouse supplies main part of electrical need of subscribes 
in this region because of tits nearness to the capital. Due to combinational cycle nature of this powerhouse and also its unique production capacity, energy return has increased through different phases of production and this matter is especial advantage of this project. This powerhouse return is 50 percent, which is the largest amount among the thermal powerhouse of country. Referring to the fact that operational activities extent of project did not make it possible for the researches to operate that project in the research standard, hence through consulting with experts, these kinds of decisions were made as part of a greater project, which would be considered as completely independent project. Therefore, the project we considered in this research is to project an industrial workshop at project site, in which an attempt is to classify and rank existing risk on project.

\subsection{Offering model and procedure of obtaining results}

In this paper, the method used for risk identification includes three main steps: (1) a step of listing different kinds of probable risk in construction projects, (2) a step of obtain each risk weight and efficacy and (3) a step of operation "R index" in order to rank risks. We will analyze each of these steps in details.

\subsubsection{First step: creation of hierarchal structure of risk}

In this step, the most important risk, which may occur in construction project, are listed to be used in the questionnaires sent to experts for weighting and scoring. The method of risk broken structure (RBS) should be introduced before listing the risks. This method is an effective tool to classify the risks, which in fact, shows a hierarchal structure of project risk. The other advantage of risk fail is to help managers understand how to distribute risks through different phases of a project. Therefore, the risks in this part are classified based on the hierarchal structure.

\subsubsection{Second step: obtaining risk weighed and efficacy}

In this step, each risk weighted and efficacy should be determined by using questionnaires. The processes are in this way that first each risk efficacy in project should be determined. Efficacy means that according to expert and specialists' opinion, the scores of the mentioned risk are obtained in terms of their influences on project. Then each risk weighted should be defined in the next step. In this step, the multi-criteria decision-making method is used to do pair comparison among risk. In this phase, the risks are compared in pairs to determine their relative importance and then they are analyzed by Analytical Hierarchal Process (AHP) to finally determine the weight of each risk. The following section presents the necessary steps of obtaining risk efficacy and weights by the AHP.

\subsubsection{Obtaining efficacy (Risk identification):}

The Likert's 5-scale has been used to obtain risks efficacy. This spectrum is in duded fire point: very low, low, mean, high and very high shown in Fig. 1.

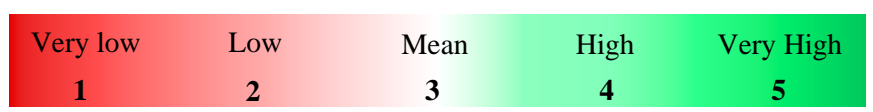

Fig.1. Likert's 5-scale spectrum

There are some questions, which need to be asked from experts in the questionnaire: "which score the risk $X$ will obtain in term of influence amount on different aspects of project? ". Because this questionnaire has been verified, hence they should be analyzed in terms of reliability and SPSS software has been used for calculating Cronbach alpha. In this step after calculating Alpha coefficient of a questionnaire to achieve an acceptable reliability and eliminating the risk which lead to unequal result in different condition. The remained risks are considered as identified risks. Here after, the reminder risks is called the project risks. Then the arithmetic means from project risks is calculated 
and figure resulted from mean is the risk efficacy that is shown by indicators $E_{k}$. $k$ is indicator of risk and $E$ is indicator of efficacy.

\subsubsection{Obtaining risk weights}

After determining efficacy of each project risks, their weight should be defined. The questionnaire is also used to do this and the questionnaire like following has asked in terms of pair comparison among risks: "How much influence and impotence has the risk $X$ in analysis in comparison with the risk $Y$ ?". In contrast with pair comparison, this one is sent to industry experts and because this questionnaire is a pair comparison, there is no need to calculate reliability of questionnaire, but its inconsistency rate must be estimated. The pair comparison among risk has been done already, which we cannot yet determine their weights. To do that, we use AHP and examine them by Super Decision software. The AHP has introduced by Satty and makes it possible to have a judgment between intangible qualitative scales and tangible quantitative ones (Badri, 2001). This analysis first divides the decision making process into a hierarchal structures of alternatives and scales. The decision-making scales, goals and alternatives are combined altogether in one hierarchal structure like organizational structure. The standard AHP has three levels including 1-total goal of issue, 2- multiple scales and 3- decisionmaker alternatives. In each level, the items are compared in pair based on their influence levels and special scales high levels (Albayrak \& Erensal, 2004). In this paper, the RBS implies the hierarchal tree for ranking and measurement of project risks. Then pair comparison among scales and alternatives should be individually done. If we suppose that we want to compare two risks A and B, the pair comparison based on the Satty’s 9-potins spectrum are as shown in Table 2.

\section{Table 2}

Satty's AHP 9 point pairwise comparison scale

\begin{tabular}{ll}
\hline Explanation & Value \\
\hline Two risks contribute equally to the objective. & 1 \\
Experience and judgment moderately favor Risk A over Risk B. & 3 \\
Experience and judgment strongly favor Risk A over Risk B. & 5 \\
Risk A is strongly favored over Risk B. & 7 \\
The evidence favoring Risk A over Risk B is of the highest possible order of affirmation. & 9 \\
Between the odd numbered relative values. & $2,4,6,8$ \\
\hline
\end{tabular}

If we consider $K$ as a number of project risks and $\left\{K_{j}=1,2, \ldots, N\right\}$, then matrix of pair comparison for $N$ risk is likes Eq. (1) in which every element of $a_{i j}=\{i, j=1,2, \ldots, n\}$ is comparison ratio of risk $i$ into risk $j$.

$$
A=\left[\begin{array}{ccccc}
a_{11} & \ldots & a_{12} & \ldots & a_{1 n} \\
\vdots & & \vdots & & \vdots \\
a_{21} & \ldots & a_{22} & \ldots & a_{2 n} \\
\vdots & & \vdots & & \vdots \\
a_{n 1} & \ldots & a_{n 2} & \ldots & a_{n n}
\end{array}\right] \quad a_{i i}=1, \quad a_{i j}=1 / a_{i j}, \quad a_{i j} \neq 0
$$

In Eq. (1), $a_{i j}$ indicates importance and influence of risk $i$ into risk $j$ in the project.

\subsubsection{Third step: using " $R$ index" for risk ranking}

As we can observe, each risk weight and efficacy was obtained in prior step. In this step, we can apply " $R$ index". The designed indicator in this study is a constant and trustworthy method for risk ranking, risk measurement as well as no confidence in projects. In this research, there is an indicator 
called " $R$ index" for measuring and ranking risks in projects, which has two parts. One part is risk efficacy and the other is risk weights which are shown by $E_{k}$ and $W_{k}$, alternatively and $k$ indicates a risk number. Finally, R index for each risk will be calculated by Eq. (2), through combining questionnaires data.

$R_{k}=E_{k} \times W_{k}$,

where $\mathrm{R}$ means how much the risk has relative importance in analysis, so a risk has higher score, has higher premiership.

\section{Research results}

In this section, we analyze the research results in accordance with methodology steps that are the sequence of data gathering and their analysis according to said steps in research methodology.

\subsection{Creating the hierarchal structure of risks}

First, all potential risks for project were defined in a hierarchal structure by RBS. So clearer image we obtained from all existing risk. In this paper, RBS levels and probable risk were classifying by managers. As it is determined in Fig. 2, 35 risks have predicted for project, which has classified into five categories.

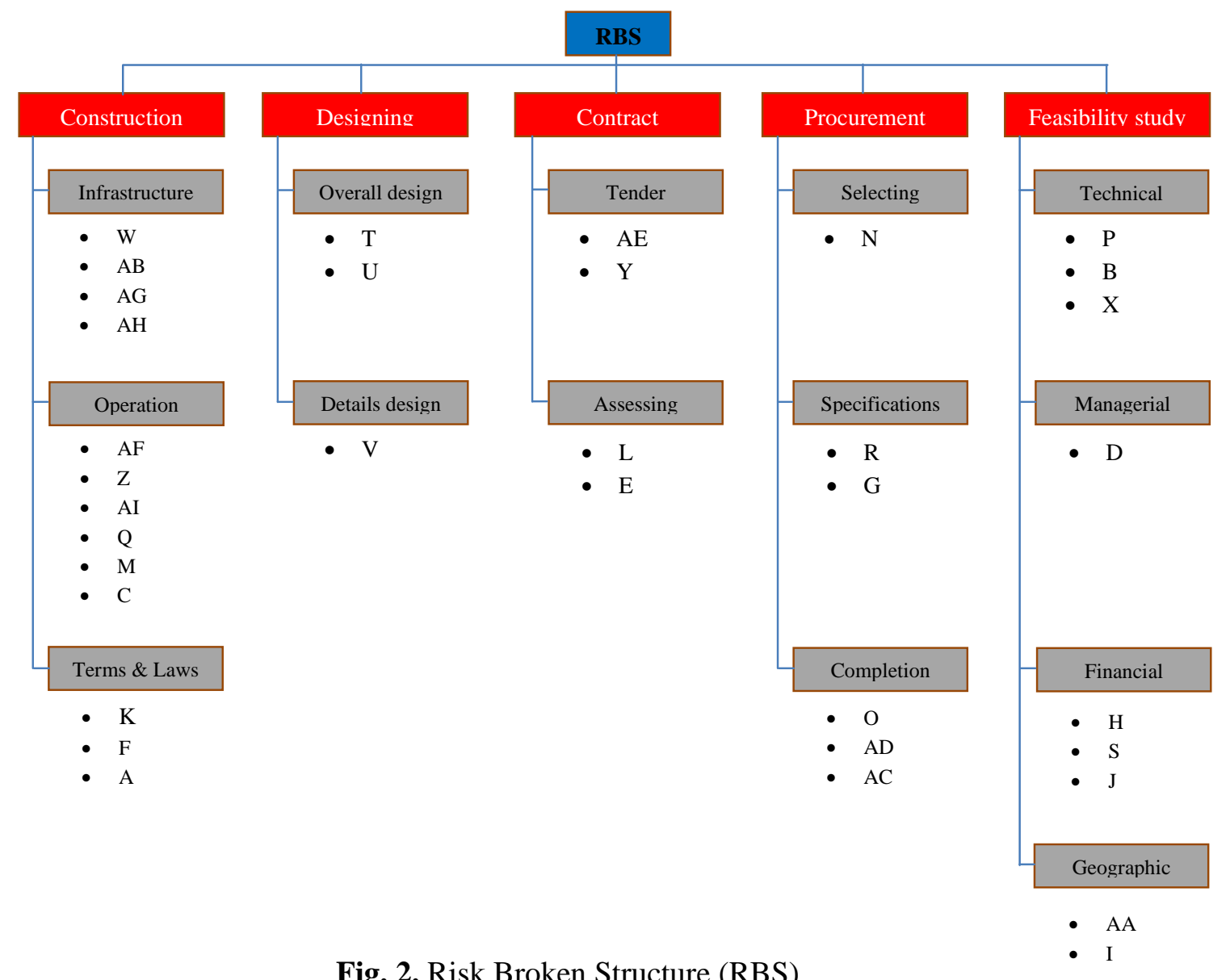

In this structure, the most probable project risks has been divided into five areas (Feasibility study, Procurement, Contract, Designing and Construction) where each has a subarea. Most of the risks are in construction areas and in operational and financial subarea. Only few of them are in designing and 
contract areas. A main question for project management team was that "how the risk analysis is ranked and how events result from it, are contracted and prevented". An importance of this case is completely clear. Since the goal of organization is cost and time saving through risk analyses, in addition to prevent the effects of negatives events in project the most important and primary risks would be chosen among identified risk for analysis. It is better to consider one concise mark for each risk and offer better image for them, before calculating risks weight and efficacy. All of the probable risks for project have been listed in Table 3.

Table 3

List of Risk and its symbol

\begin{tabular}{|c|c|}
\hline Risk & Symbol \\
\hline Picket and strikes & A \\
\hline Inappropriate technology & $\mathrm{B}$ \\
\hline One of the parties' bankrupting & $\mathrm{C}$ \\
\hline Management Weaknesses & $\mathrm{D}$ \\
\hline Political Considerations in Contractors assessing & $\mathrm{E}$ \\
\hline Changes in local and state laws & $\mathrm{F}$ \\
\hline Incorrect estimation of Amount of material needed & G \\
\hline Incorrect estimating of sponsor’s financial ability & $\mathrm{H}$ \\
\hline Insecurity Project Zone & I \\
\hline Change in tax rate & $\mathrm{J}$ \\
\hline Political events & $\mathrm{K}$ \\
\hline Lack of appropriate metrics for Contractors assessing & $\mathrm{L}$ \\
\hline Financial misuse & M \\
\hline Lack of appropriate metrics for Suppliers assessing & $\mathrm{N}$ \\
\hline Incorrect Scheduling of raw material supply & $\mathrm{O}$ \\
\hline unavailability of labor & $\mathrm{P}$ \\
\hline Delay in bill payment by employer & Q \\
\hline Partial transfer specification to suppliers & $\mathrm{R}$ \\
\hline Economic changes / change of interest rate, currency and economic inflation & $\mathrm{S}$ \\
\hline Inappropriate Design Technology & $\mathrm{T}$ \\
\hline Improper Project design & $\mathrm{U}$ \\
\hline Error in transfer overall design into Detailed design & V \\
\hline Poor planning system & W \\
\hline Ignoring the technology's price & $\mathrm{X}$ \\
\hline Incorrect estimation of activities cost & $\mathrm{Y}$ \\
\hline machinery and equipment impairment & Z \\
\hline Ignoring the project's environmental conditions & AA \\
\hline Poor informational system & $\mathrm{AB}$ \\
\hline Material failure & $\mathrm{AC}$ \\
\hline Delays in transporting raw materials & $\mathrm{AD}$ \\
\hline Incorrect estimation of activities time & $\mathrm{AE}$ \\
\hline Poor weather conditions & $\mathrm{AF}$ \\
\hline Weakness in the payroll system & AG \\
\hline No specific relationships & $\mathrm{AH}$ \\
\hline Events for labor & $\mathrm{AI}$ \\
\hline
\end{tabular}




\subsection{Obtaining efficacy (Risk identification):}

For applying " $\mathrm{R}$ index", first we should determine risks efficacy. So a questionnaire was distributed among 37 experts of whom 27 experts returned their questionnaires. Since the number of questionnaires was below 30, so their reliability should be estimated. To calculate questionnaire reliability, Cronbach alpha should be calculated by SPSS software. Table 4 is a summary alpha calculations and elimination of risk which may increase it.

Table 4

Eliminated Risks by Calculating Cronbach Alpha

\begin{tabular}{l|lll|l}
\hline Iteration & Eliminated Risk & $\begin{array}{l}\text { Alpha, } \\
\text { before elimination }\end{array}$ & $\begin{array}{l}\text { Alpha, } \\
\text { after elimination }\end{array}$ & Remained Risks \\
\hline First & N & 0.469 & 0.522 & 34 \\
Second & AB & 0.522 & 0.554 & 33 \\
Third & $\mathrm{D}$ & 0.554 & 0.579 & 32 \\
Fourth & $\mathrm{W}$ & 0.579 & 0.606 & 31 \\
Fifth & $\mathrm{U}$ & 0.606 & 0.626 & 30 \\
Six & $\mathrm{L}$ & 0.626 & 0.639 & 29 \\
Seven & $\mathrm{R}$ & 0.639 & 0.654 & 28 \\
Eighth & $\mathrm{T}$ & 0.654 & 0.668 & 27 \\
Ninth & $\mathrm{V}$ & 0.668 & 0.685 & 26 \\
Tenth & $\mathrm{O}$ & 0.685 & 0.697 & 25 \\
Eleventh & $\mathrm{B}$ & 0.697 & 0.708 & 24 \\
\hline
\end{tabular}

It is necessary to note that risks elimination was stopped when Cronbach alpha amount was 0.7. As it shown in Table 4, eliminated risks increased Cronbach alpha coefficient. So we continue with 24 remained risks. Then obtained results of alternatives relating to an efficacy amount of the reminded risks, were gathered and arithmetic mean has been considered for each risk. Finally, the results from expert's ideas about the remained risks efficacy have been shown in Table 5.

Table 5

Calculated Risk’s Efficacy

\begin{tabular}{ll|ll|ll}
\hline Risk & $\begin{array}{l}\text { Efficacy } \\
\text { Score }\end{array}$ & Risk & $\begin{array}{l}\text { Efficacy } \\
\text { Score }\end{array}$ & Risk & $\begin{array}{l}\text { Efficacy } \\
\text { Score }\end{array}$ \\
\hline A & 2.89 & K & 3.07 & AA & 2.81 \\
C & 3.30 & M & 3.26 & AC & 2.85 \\
E & 3.07 & P & 2.59 & AD & 2.00 \\
F & 3.22 & Q & 3.41 & AE & 3.19 \\
G & 2.89 & S & 3.56 & AF & 3.00 \\
H & 3.37 & X & 3.11 & AG & 2.78 \\
I & 2.74 & Y & 3.33 & AH & 3.11 \\
J & 2.81 & Z & 2.56 & AI & 3.11 \\
\hline
\end{tabular}

The results of Table 5 show that the risk "economic changes / change of interest rate, currency and economic inflation" has high importance from of view of all persons involved in project management team. In other word, if this risk occurs in project, the project may confront with the most threat.

\subsection{Obtaining risk weights:}

Now, each risk weight should be determined by pair comparison questionnaire. This questionnaire was distributed among 10 experts, obtained result from experts opinion relating to risk importance in 
comparison to each other are gathered and an arithmetic mean is calculated for each pair comparison. The final data of pair comparison among risks are shown in Appendix in Table (A.1). Table (A.1) shows the pair comparison among risks and finally after doing the hierarchal analysis in super decision software, risks weights were obtained which is shown in Table 6.

Table 6

Calculated Risk’s weight by Super Decision Software

\begin{tabular}{|c|c|c|c|c|c|}
\hline Risk & Weight & Risk & weight & Risk & weight \\
\hline A & 0.028 & K & 0.025 & AA & 0.029 \\
\hline C & 0.033 & M & 0.027 & AC & 0.030 \\
\hline E & 0.022 & $\mathrm{P}$ & 0.026 & $\mathrm{AD}$ & 0.028 \\
\hline $\mathrm{F}$ & 0.027 & Q & 0.120 & $\mathrm{AE}$ & 0.027 \\
\hline G & 0.027 & $\mathrm{~S}$ & 0.124 & AF & 0.029 \\
\hline $\mathrm{H}$ & 0.104 & $\mathrm{X}$ & 0.028 & AG & 0.026 \\
\hline I & 0.024 & $\mathrm{Y}$ & 0.115 & $\mathrm{AH}$ & 0.023 \\
\hline $\mathrm{J}$ & 0.023 & $\mathrm{Z}$ & 0.027 & AI & 0.028 \\
\hline
\end{tabular}

\subsection{Using “ $R$ index" for risk ranking:}

In previous steps, each risk weight and efficacy was obtained. In this section " $\mathrm{R}$ index" introduced methodology step is applied on each risk to determine an indicator for risk ranking in accordance with each of them. After applying "R index" for each risk, final ranking was obtained which is shown in Table 7.

\section{Table 7}

Calculating "R index" for each Risk

\begin{tabular}{l|lll|l}
\hline Risk & Efficacy & Weight & R index & Priority / Rank \\
\hline A & 2.89 & 0.028 & 0.0809 & 14 \\
C & 3.30 & 0.033 & 0.1089 & 5 \\
E & 3.07 & 0.022 & 0.0675 & 20 \\
F & 3.22 & 0.027 & 0.0869 & 9 \\
G & 2.89 & 0.027 & 0.0780 & 15 \\
H & 3.37 & 0.104 & 0.3505 & 4 \\
I & 2.74 & 0.024 & 0.0658 & 22 \\
J & 2.81 & 0.023 & 0.0646 & 23 \\
K & 3.07 & 0.025 & 0.0768 & 16 \\
M & 3.26 & 0.027 & 0.0880 & 6 \\
P & 2.59 & 0.026 & 0.0673 & 21 \\
Q & 3.41 & 0.120 & 0.4092 & 2 \\
S & 3.56 & 0.124 & 0.4414 & 1 \\
X & 3.11 & 0.028 & 0.0871 & 7 \\
Y & 3.33 & 0.115 & 0.3830 & 3 \\
Z & 2.56 & 0.027 & 0.0691 & 19 \\
AA & 2.81 & 0.029 & 0.0815 & 13 \\
AC & 2.85 & 0.030 & 0.0855 & 11 \\
AD & 2.00 & 0.028 & 0.0840 & 12 \\
AE & 3.19 & 0.027 & 0.0861 & 10 \\
AF & 3.00 & 0.029 & 0.0870 & 8 \\
AG & 2.78 & 0.026 & 0.0723 & 17 \\
AH & 3.11 & 0.023 & 0.0715 & 18 \\
AI & 3.11 & 0.028 & 0.0871 & 7 \\
\hline
\end{tabular}

The results of risk last ranking imply an important issue, which is clearly observable. Risk ranks showed that first six great risk among 24 risk in ranking relate to economic and financial issues of project, including "economic changes / change of interest rate, currency and economic inflation” , “ delay in bill payment by employer” , “ incorrect estimation of activities cost” ,” incorrect estimating of sponsor's financial ability”," one of the parties' bankrupting” and " financial misuse”. This 
implies that financial and economic issues if project, are the most important factors in occurring risk in project and in the other words, considering financial issues is Achilles heel in the construction project. The firm expected also to confront with the financial risk through operating project. So it attempts to offer some proper device and facilities to face with such risks. Regarding achieved ranking, it is suggested to firm to choose one risk among 6 great risks in order to simulate project and to anticipate and analyze situation.

\section{Discussion and conclusion}

In this research, first in the meeting with operational consultant of project, 35 risks were identified and then the risks were identified and their efficacies were obtained by sending first questionnaire. Then by sending the other questioner and software analysis, risks weights' were calculated. The primary objective of operating research was that the managers of project pay more attention to risks while have higher importance in comparison with other ones. Since considering all risks may decrease efficiency and effectiveness of risk analysis or may lead to paying attention to less important risks. However, the risks were classified based on 2 factors by the help of this indicators, "the efficacy in project" and "risks weights as a result of pair comparison" and this implies that higher scored risks have more importance for analysis and managers can analysis the probable risks of project on this ranking and internal facilities of their own firm. In this paper, in addition to the political risks examined by Ashley and Bonner (1987) and financial risks considered by Kapila and Hendrickson (2001), the common risks were also analyzed. In addition, the offered indicator in this study was more simple and understandable than said indicator in Jiahao Zeng's paper (2007). Furthermore, unlike said indicators by Sebastian Maniasi (2006), this one introduced a complete definition for risks identification. Finally, because of using many experts' opinion through operating steps of this research, there are fewer objections about non-justifiability, less irrevocable questionnaire and less using of expert's ideas, the objection or problem which was obvious in Long and Fischhoff's (2000) research.

At the end we can conclude that the difference between obtained scored of risks showed that there was a considerable convergence between risks. As seen in Fig. 3, from 4 primary risks which all were related to financial risks, three of them were mostly dependent to the firm financial issues and the other was depended to the economic issues of government and country.

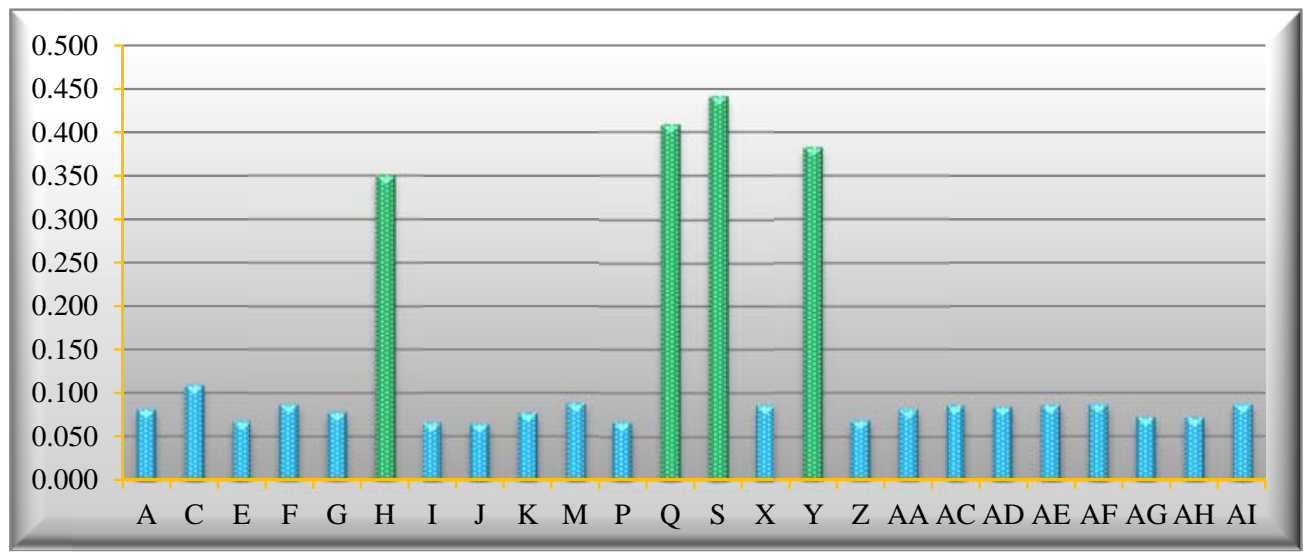

Fig. 3. Histograms of Risk’s R index

We could previously claim that the financial and economic risks are involved in the important ones, but the result sealed this claim and implied that there was a tremendous difference between the importance of economic risks and the other risks. The most important reason of this difference is lack of economic stability in country and lack of economic-political relations with precursor country and organization in the field of construction project. Therefore, it is suggested that more analysis are performed by project experts through phases of possibility measurement, design, financial issues support, financial demand recovery trend by 
employer, and the most important of all, to have ability to offer the proper devices for confronting such risks through simulation of project situation.

\section{Acknowledgements}

The research was financed by Imam Khomeini International University of Ghazvin No. 751022-91. The authors gratefully acknowledge the financial support for this work.

\section{Reference}

Albayrak, E., \& Erensal, Y.C. (2004). Using analytic hierarchy process (AHP) to improve human performance. An application of multiple criteria decision making problem. Journal of Intelligent Manufacturing, 15, 491-503.

Ashley, D.B., \& Bonner, J.J. (1987). Political risks in international construction. ASCE Journal of Construction and Engineering Management ,113(9), 447-467.

Badri, M.A. (2001). A combined AHP-GP model for quality control systems. International Journal of Production Economics, 72, 27-40.

Burke, R. (2003). Project management Planning \& Control Techniques. John Wiley \& Sons; $4^{\text {th }}$ ed.

Chapman, C. (2006). Key points of contention in framing assumptions for risk and uncertainty management. International Journal of Project Management, 24(4), 303-313.

Daniel, W.M., Albert, P.C., Patrick, T.I., Lam, John F.Y. \& Yeungb, J.H.L. (2011). Risk ranking and analysis in target cost contracts: Empirical evidence from the construction industry. International Journal of Project Management, 29(6), 751 -763.

Dias, A., Ioannou, P. (1995). A desirability model for the development of privately-promoted infrastructure projects. Civil \& Environmental Engineering Department, University of Michigan, Ann Arbor, Michigan 48109-2125, U.S.A.

Khazaeni, G., Khanzadi, M., \& Afshar, A. (2012). Fuzzy adaptive decision making model for selection balanced risk allocation. International Journal of Project Management, 30(4), 511-522.

Jebel Ameli, M.S., Rezaeifar, A., \& ChaeiBakhsh, A. (2005). Risk ranking with the multi-criteria decision-making. Second International Conference on Project Management, Tehran, Iran.

Kapila, P., \& Hendrickson, C. (2001). Exchange rate risk management in international construction ventures. ASCE Journal of Construction Engineering Management, 17(4), 186-91.

Lam, K., Wang, D., Patricia, Y., \& Tsang, T. (2007). Modeling risk allocation decision in construction contracts. International Journal of Project Management, 25, 485-493.

Long., J., \& Fischhoff, B. (2000). Setting Risk Priorities: A Formal Model. Risk Analysis, 20(3), 339352.

Makoei, A., Mahdavi, I., \& Farokhian, F. (2007). Appropriate allocation of risk to the contractor and the employer. Fourth International Conference on Project Management, Tehran, Iran.

Makoei, A, \& Mojtahedi, MH. (2007). New techniques are introduced and applied to identify project risks. First International Conference on Risk Management, Tehran, Iran.

Maniasi, S., Britos, P., \& García Martínez, R. (2006). A Taxonomy-Based Model for Identifying Risks. Buenos Aires Institute of Technology.

Motawa, I.A., Anumba, C.J., \& El-Hamalawi, A. (2006). A fuzzy system for evaluating the risk of change in construction projects. Advances in Engineering Software, 37(9), 583-591.

Newtown, S. (2008). A Guide to the Project Management Body of Knowledge (PMBOK). American National Standard ANSI/PMI 99-001.

Project Risk Management Handbook. (2003). Office of Project Management Process Improvement, First Edition, Revision 0, June 26.

Ralph, L. Kliem, I., \& Ludin, S. (2010). Project Management Practitioner's Handbook. AMACOM Publisher.

Webb, A. (2003). The Project Manager’s Guide to Handling Risk. Gower Publishing, Ltd. 
624

Zeng, J., An, M., \& Smith, N.J. (2007). Application of a fuzzy based decision making methodology to construction project risk assessment. International Journal of Project Management, 25, 589600 .

\section{Appendix}

\begin{tabular}{|c|c|c|c|c|c|c|c|c|c|c|c|c|c|c|c|c|c|c|c|c|c|c|c|c|}
\hline & A & $\mathrm{C}$ & $E$ & F & G & $\mathrm{H}$ & I & $J$ & $\mathbf{K}$ & $\mathbf{M}$ & $\mathbf{P}$ & $\mathbf{Q}$ & $\mathrm{s}$ & $\mathrm{X}$ & $\mathbf{Y}$ & $\mathrm{z}$ & AA & $\mathbf{A C}$ & $\mathrm{AD}$ & $\mathrm{AE}$ & $\mathbf{A F}$ & AG & AH & AI \\
\hline A & & 0.73 & 0.60 & 0.43 & 0.81 & 0.25 & 2.11 & 0.75 & 1.20 & 0.85 & 3.06 & 0.18 & 0.20 & 0.44 & 0.21 & 2.15 & 2.00 & 0.64 & 1.35 & 1.15 & 1.83 & 0.89 & 1.10 & 0.85 \\
\hline C & & & 2.73 & 2.68 & 1.11 & 0.21 & 0.97 & 1.45 & 1.14 & 1.58 & 1.94 & 0.22 & 0.21 & 1.34 & 0.24 & 0.49 & 1.49 & 1.03 & 1.77 & 0.61 & 0.90 & 3.29 & 1.36 & 0.44 \\
\hline E & & & & 0.40 & 0.69 & 0.22 & 0.85 & 1.15 & 1.03 & 0.89 & 1.00 & 0.17 & 0.17 & 0.47 & 0.21 & 0.76 & 0.51 & 1.77 & 0.57 & 1.15 & 0.60 & 1.44 & 0.98 & 0.86 \\
\hline $\mathrm{F}$ & & & & & 0.40 & 0.21 & 0.66 & 1.21 & $\begin{array}{l}1.02 \\
\end{array}$ & 0.77 & 0.42 & 0.15 & 0.17 & $\begin{array}{l}1.47 \\
1.66\end{array}$ & 0.20 & 0.98 & $\begin{array}{l}1.71 \\
\end{array}$ & 1.39 & 1.48 & 0.89 & $\begin{array}{l}0.30 \\
1.37\end{array}$ & $\begin{array}{l}1.47 \\
\end{array}$ & 1.00 & $\begin{array}{l}.000 \\
1.15\end{array}$ \\
\hline G & & & & & & 0.19 & 0.95 & 0.25 & $\begin{array}{l}1.09\end{array}$ & 2.50 & $\begin{array}{l}1.15 \\
\text { S }\end{array}$ & 0.21 & 0.16 & 1.08 & 0.18 & 0.74 & 0.78 & 0.66 & 0.58 & 1.73 & 0.68 & 1.50 & 1.89 & 0.65 \\
\hline H & & & & & & & 3.91 & 4.54 & 3.19 & 6.13 & 4.70 & 1.06 & 0.62 & 3.40 & 0.63 & 4.91 & 5.55 & 3.81 & 5.23 & 4.08 & 2.64 & 3.29 & 4.46 & 3.61 \\
\hline I & & & & & & & & 0.57 & 0.74 & 0.64 & 0.97 & 0.19 & 0.21 & 1.37 & 0.28 & 1.38 & 0.54 & 0.44 & 0.89 & 1.01 & 0.96 & 1.76 & 0.88 & 0.76 \\
\hline $\mathbf{J}$ & & & & & & & & & 1.02 & 0.26 & 0.94 & 0.25 & 0.18 & 0.40 & 0.18 & 0.40 & 0.47 & 0.44 & 0.47 & 0.47 & 0.82 & 1.17 & 1.33 & 0.41 \\
\hline $\mathbf{K}$ & & & & & & & & & & 0.81 & 0.38 & 0.23 & 0.20 & 1.02 & 0.18 & 1.19 & 0.53 & 0.94 & 0.68 & 0.80 & 1.92 & 1.01 & 2.90 & 1.11 \\
\hline M & & & & & & & & & & & 1.18 & 0.20 & 0.17 & 1.03 & 0.22 & 0.88 & 0.88 & 1.08 & 0.71 & 0.83 & 0.74 & 1.20 & 1.83 & 1.60 \\
\hline $\mathbf{P}$ & & & & & & & & & & & & 0.20 & 0.16 & 2.28 & 0.20 & 0.69 & 0.51 & 0.37 & 1.45 & 0.72 & 1.37 & 0.57 & 1.39 & 1.44 \\
\hline$Q$ & & & & & & & & & & & & & 0.97 & 3.72 & 0.83 & 4.52 & 6.51 & 5.91 & 4.95 & 6.32 & 3.95 & 4.15 & 5.88 & 3.60 \\
\hline s & & & & & & & & & & & & & & 5.07 & 1.97 & 3.31 & 4.72 & 3.46 & 4.63 & 5.22 & 3.84 & 3.52 & 4.01 & 4.77 \\
\hline $\mathrm{x}$ & & & & & & & & & & & & & & & $\begin{array}{l}0.19 \\
0.9\end{array}$ & $\begin{array}{l}.31 \\
1.71\end{array}$ & $\begin{array}{l}4.72 \\
0.49\end{array}$ & $\begin{array}{l}0.40 \\
0.57\end{array}$ & $\begin{array}{l}1.03 \\
1.03\end{array}$ & 0.89 & $\begin{array}{l}3.04 \\
0.43\end{array}$ & $\begin{array}{l}.352 \\
0.89\end{array}$ & $\begin{array}{l}4.01 \\
0.42\end{array}$ & 0.90 \\
\hline $\mathbf{Y}$ & & & & & & & & & & & & & & & & 3.89 & 5.15 & 3.83 & 4.57 & 5.37 & 4.71 & 4.72 & 2.93 & 4.73 \\
\hline $\mathbf{Z}$ & & & & & & & & & & & & & & & & & 0.56 & 1.00 & 0.32 & 1.10 & 0.60 & 0.95 & 0.91 & 2.21 \\
\hline AA & & & & & & & & & & & & & & & & & & 0.54 & 0.69 & 1.01 & 0.71 & 1.18 & 1.53 & 0.97 \\
\hline AC & & & & & & & & & & & & & & & & & & & 0.83 & 1.46 & 0.34 & 0.59 & 0.72 & 1.23 \\
\hline AD & & & & & & & & & & & & & & & & & & & & 1.38 & 0.67 & 1.10 & 0.71 & 0.43 \\
\hline $\mathbf{A E}$ & & & & & & & & & & & & & & & & & & & & & 0.81 & 1.36 & 2.78 & 1.30 \\
\hline AF & & & & & & & & & & & & & & & & & & & & & & 1.24 & 0.88 & 1.16 \\
\hline AG & & & & & & & & & & & & & & & & & & & & & & & 2.94 & 1.55 \\
\hline $\mathrm{AH}$ & & & & & & & & & & & & & & & & & & & & & & & & 1.07 \\
\hline AI & & & & & & & & & & & & & & & & & & & & & & & & \\
\hline
\end{tabular}

